\title{
Managed Learning Environments in Universities: Are they Achievable?
}

\author{
Ray Stoneham \\ University of Greenwich, School of Computing \& Mathematical Sciences
}

\section{Introduction}

JISC'S "MLES for Lifelong Learning" project (JISC, 2006) defines a virtual learning environment (VLE) as the components of an online information system in which learners and tutors participate in interactions of various kinds including online learning, and a managed learning environment (MLE) is defined as embracing the whole range of information systems and processes (including the VLE) that contribute directly or indirectly to learning and learning management. A MLE therefore includes student record systems, register and library systems, with a clear emphasis on integration, processes and quality assurance (QA).

MLEs in universities have been recognised as providing many benefits (JISC, 2006), but few universities would claim to have successfully introduced one throughout the institution. The enormity of the task is daunting, and the attractiveness of competing open social Web 2.0 resources such as FaceBook and Twitter has made it hard to stay focused on corporate solutions when new user-centred "cool" tools are becoming available that are outside the firewall. Weller (2007) has used the term VLE 2.0 to describe a VLE with added Web 2.0 functionality, and points out that a single integrated system will always lag behind state-of-the-art social Web 2.0 offerings. However, security, confidentiality, intellectual copyright and data protection are just some of the reasons a university may decide that a MLE is preferable to a collection of cloud-based open Web 2.0 systems.

Smaller institutions such as FE colleges and faculties or schools within universities have often been more successful in implementing MLEs (JISC, 2005). The School of Computing \& Mathematical Sciences (CMS) at the University of Greenwich has developed a very successful MLE over the past ten years. The School is of average size (6000 students, 200 academic staff) with its own small dedicated IT technician and administration teams and a lecturer (the author) who has worked with all the stakeholders, and with the support of the Dean and other managers, to develop a mature system that meets many of the needs of the School. Local partner college staff and students have restricted access to the CMS VLE, and international CMS Collaborations staff and students have a separate MLE to reflect the different business processes currently involved.

\section{The Case Study}

This case study identifies the main aspects of the CMS MLE, and gives details of the benefits it provides. The CMS MLE has ad hoc links to a range of corporate IT systems to ensure current student and course data is used, and provides much added value to School managers, administrators, lecturers and students. It is a key component of the School's QA systems. It could be seen as a prototype, parts of which could 
be scaled up and fully integrated into corporate systems to provide an MLE solution for a university. Preliminary discussions have taken place with central services for the University of Greenwich to take this forward and a prototype core system is currently being developed.

The CMS MLE has evolved organically, and many parts of it are in need of re-engineering. The interface lacks consistency, the styling is old fashioned and the information architecture needs revising. However, for an MLE it is the functionality that is key to its success, and this has been the priority. There are plans for a redesign of the system when resources permit, particularly for mobile access.

The CMS MLE incorporates a custom-made virtual learning environment that provides many of the benefits of other VLES and is therefore not discussed here. In any case, the current VLE will be phased out as the university consolidates to a Moodle VLE for the next academic year. Moodle has a user-centred constructivist learning focus (Moodle, 2012) and is therefore not a good candidate for a MLE which needs an institutional focus. Moodle can, however, be an important component of a MLE.

\section{Key Implementation Issues}

Key issues for a successful MLE as identified in this case study are as follows. These supplement those identified by JISC (2006), but are more implementation specific to show what has worked in practice for CMS.

\section{Keep it simple}

Systems need to be as simple as possible. The CMS register system, for example, does not allow editing of class registers after they have been completed, thereby encouraging staff to fill them in correctly first time. Resources need to be focused on functionality with a simple interface. The CMS MLE is a basic textbased web system that meets accessibility criteria and has good usability.

\section{Ensure data is accurate and only stored in one place}

Accurate data is essential, and this needs to be maintained centrally (eg corporate student and course data), locally (eg course coordinators and moderators) and individually by staff (eg own research interests) and students (eg an MP3 recording of the pronunciation of their name).

\section{Ensure data can be accessed easily}

Data needs to be stored transparently, and the system needs to be personalised. Students need to see what is stored about them, staff should see what they need to know and managers need to have an overview of the status of systems, with the facility to drill down for more detail. Information about students is best not stored in staff e-mail inboxes, or on laptops or in network areas where it is inaccessible by other staff.

\section{Create clear QA roles and procedures}

QA roles need to be clearly defined and used in a role-based security system to provide functionality on a "need to know" basis. In the CMS MLE in most cases the initiator of a process is the course coordinator, and the QA is provided by the relevant moderator, with an administrator overseeing the process, and managers having access to relevant reports. 


\section{Keep it secure and legal}

Legal issues of data protection and accessibility need to be taken into account, and confidentiality must be maintained where appropriate.

6. Establish the best workflow for each system

The complete lifecycle of objects in the system (eg coursework, projects, examination papers) needs to be considered "from the cradle to the grave" and the most efficient and simple workflow between the people based on their roles should be implemented. This is not an easy task, and may involve significant consolidation or changes to working practices.

7. Listen to the users

Feedback from users needs to be responded to quickly to fix bugs and provide new functionality as needs change.

\section{Keep audit information}

Managers investigating complaints need to know when something was done, who did it, and what they did. Most of the CMS MLE systems store this audit information, and once data is committed to the system it cannot normally be deleted.

9. Use e-mail as a notification system

Educate staff and students to use the online systems, and make e-mail merely a notification system and not a way of transferring the data itself.

10. Show the benefits

Success is achieved if existing staff cannot imagine how they managed without the MLE, and new staff use it intuitively with minimal training.

\section{The Technology}

The technology to develop a MLE must be appropriate to the context. In the case of the CMS MLE, for historical reasons this is an intranet built using classic ASP and Microsoft Access. Current integration with corporate systems has involved ODBC connections with lookups to data in some cases, and downloads of corporate data overnight to synchronise with the CMS register and coursework systems. New systems are, however, being developed using Microsoft ASP.NET, SQL Server and SharePoint to facilitate future integration with corporate systems.

\section{The Systems}

Some of the systems that have been most successful include:

\section{The Registers System}

2. An attendance register is managed and recorded by the course coordinator and tutors. Registers are printed and used as a "turn around" document leading to data input using a web form. The list of students is synchronised overnight with the corporate student records system. Students can notify reasons for absence. This is a key resource to measure student engagement, and is vital for meeting the demands of the UK Border Agency. 


\section{The student profile}

\section{Ray Stoneham}

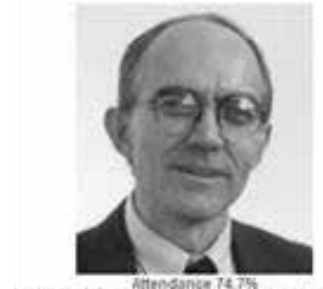

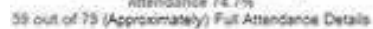

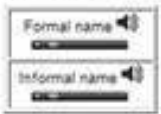

Oversess student Postpraduste

P11518 MSc intormation Technology with Security Stage 1 (Full Time)

Programme Leader is Tatians Simmonds

Registration number 000123456

Registration Status: OK

Status this year Continaing stadent

Ste: Greenwich Schoot CMS Departhent CIS

s6040 $\mathrm{E}$ si6segreenwich ac uk

CMS contact info: None provided

Unbe web space A I is wab space 2

Log of Use: Student intranet / CluS Labs

Course Grades: From Banner (excludes provisional prades, very sibw.

Protessional Deveiopment Activities: Add

Extenuating Circumstancess None this year

Course Change Requests. 1 View Detals, or Add Anceher Alecuest

Assessment Summary

Assessment Offences: None

PAB report(s) : X201100170 i X201100170: Annotated

Enquiries: Detais (5) | Add an enquiry.

Masters Prolect Due: Jas 2012

Supervisor: Ray Stoneham Projact Detais

Personal Tutor is Age Rawa:

Student Record: Add

Regiater and Upload isformation: Wencot teesback ! wth teedback

CMS Courses Attached in Register System

Other courses may be attached in Banner Attached in Banner $\mid$ COUP1252 Term 1 CRE 11406 Project Pestoraduste Programmes in issuu Department Attached in Banner Coup1416 Term 1 CPak 11471 Systems Arentectures

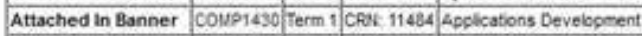

Attached In Banner CowP1432 Term 1 CoOr 11486 Systems Planning and Management

Attached in Banner CouP1444 Term 1 CPer 11495 internet and Web Technelogies (Open Source)

Figure 1 Example student profile

The profile includes as much relevant information in one place as possible. This includes the student's programme of study, their photograph and how to pronounce their name, any extenuating circumstances or assessment offences, the log of their use of the VLE, their coursework submissions and feedback from tutors, any enquiries they have made and the response, and their class attendance records and grades. A student can access their own profile in full. Staff, depending on their role, can access a subset of the information for a subset of students. 


\section{The course profile}

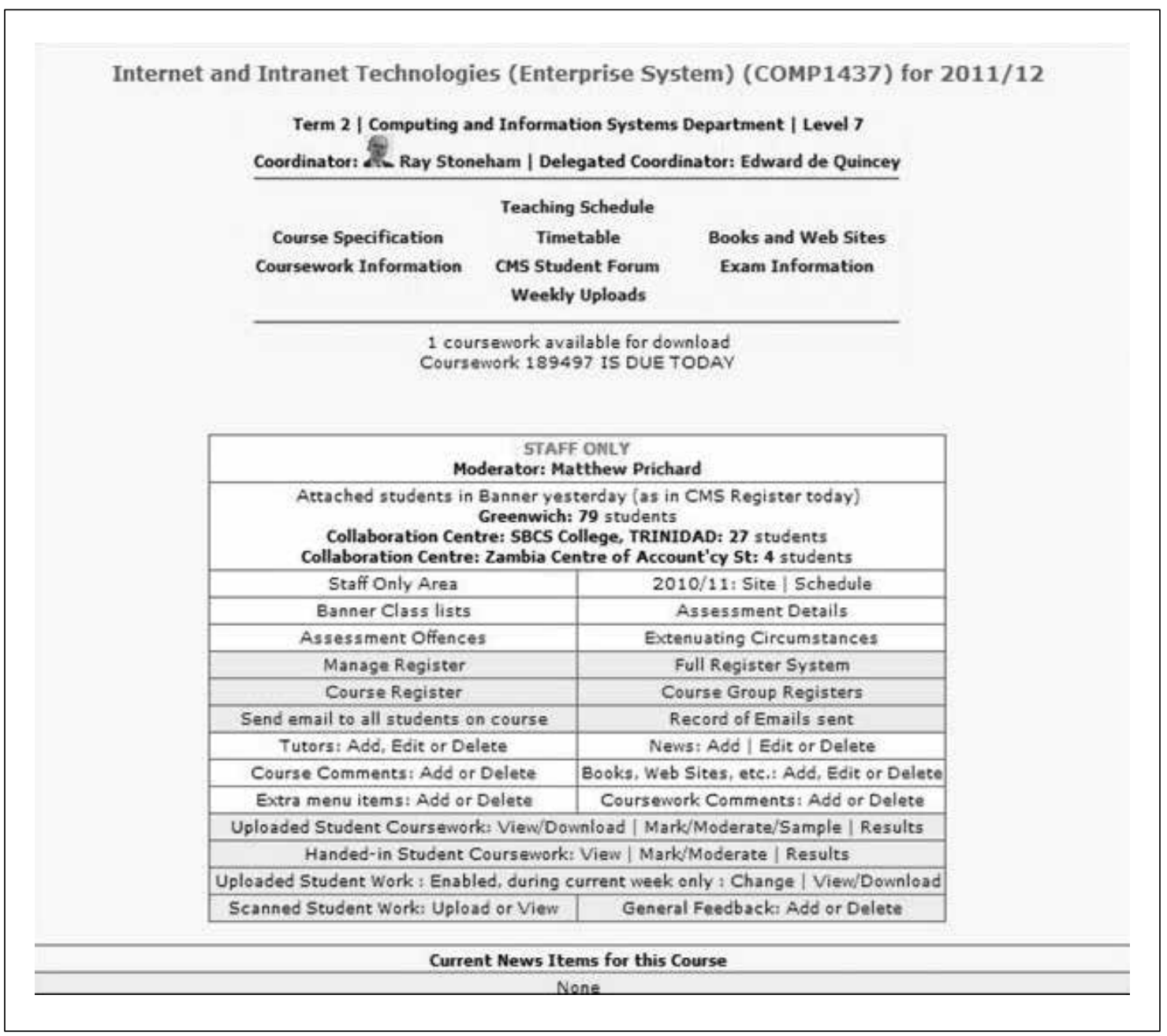

Figure 2 Example course profile

This includes all things relevant to the course, including the course specification, book lists, teaching material, assessment details, registers, assessment offences and extensions. Some of this information is restricted to staff, and some is further restricted to the relevant course coordinator, administrator or manager. 


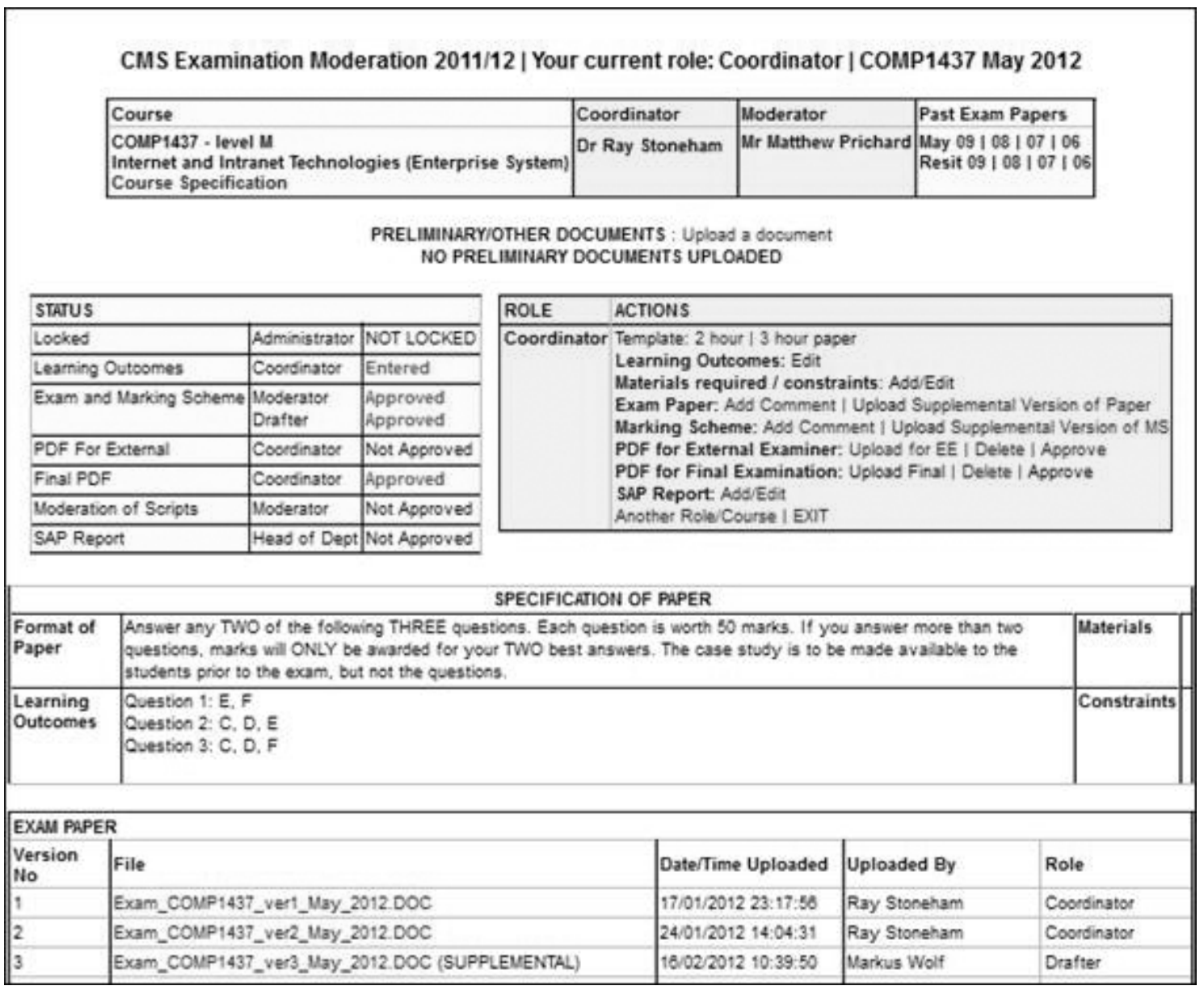

Figure 3 Coordinator view of Examination Moderation System

For over 200 exam papers per year coordinators upload papers, moderators comment on them and approve them once they are satisfied with their quality and appropriateness, managers then review these and administrators format and print them, and send them to the external examiners for approval. This system is the most secure system in the CMS MLE. Past papers are easily made available to students at the end of the examination period.

\section{The coursework moderation system}

For over 400 courseworks per year, leading to over 30,000 uploads by students, coordinators upload specifications, moderators approve them, which automatically makes the specification available to students via the VLE. Students upload their work by the due date, coursework is automatically printed if requested or marked online, and marks are input by the tutors, moderated as appropriate and transferred to the corporate Student Records System by administrators. Tutors can give feedback in a variety of forms (text, annotated documents, sound or video recordings). 
7. The eSupervision system for projects

For over 800 projects per year, project students are allocated a supervisor and interact with their supervisor via a dedicated messaging system. Records of meeting are recorded, and staged uploads and student blogs are encouraged. This system is particularly useful in allowing other staff to support students over the summer or when supervisors are away on business. A range of reports allows progress of a cohort of students to be monitored and corrective action taken if necessary.

\section{The Enquiries system}

Over 1400 students per year use a simple enquiry system to communicate with staff rather than send e-mails. This avoids students asking the same question of lots of staff in the hope that one of them will give them the answer they want.

\section{The Assessment Offences system}

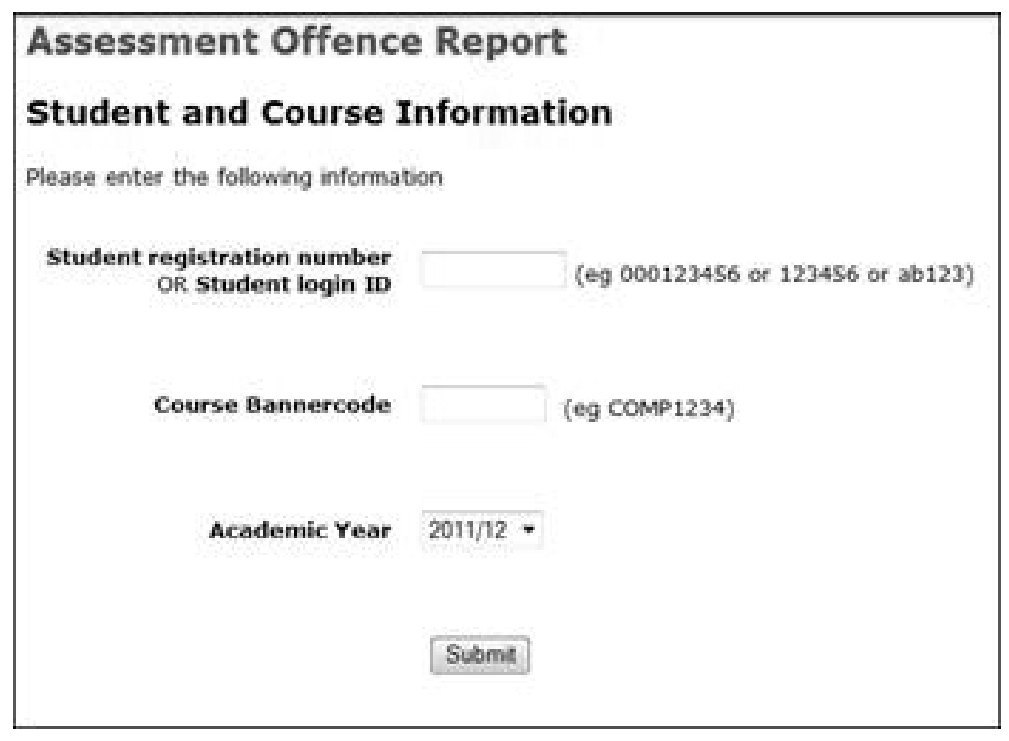

Figure 4 Form to submit details of a suspected Assessment Offence

A simple system is used by tutors to upload coursework to Turnitin and to report any assessment offences, thereby enabling these to be dealt with fairly and consistently.

\section{The Extenuating Circumstances system}

Students submit claims and upload evidence in the form of scanned documents or other images. Decisions are made promptly and the student is notified by e-mail. 


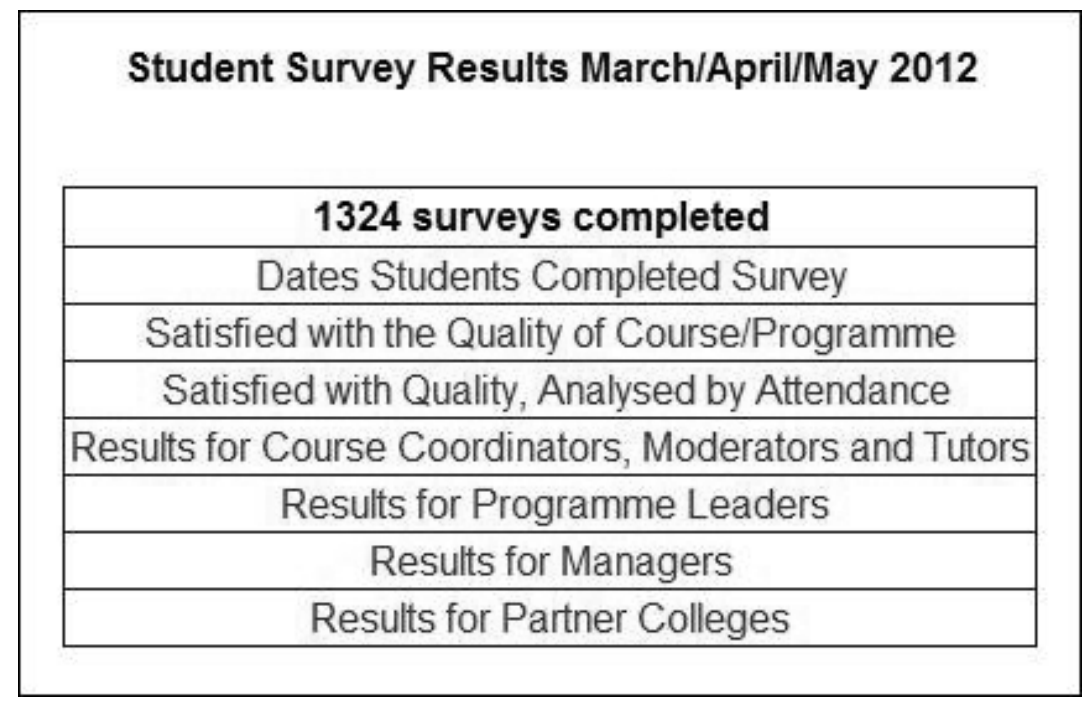

Figure 5 Main staff menu for the Student Survey

Over 1300 students per year complete a series of questions (similar to the NSS) about their experience of their programme of study, and about each of their courses. They are encouraged to complete the survey every time they login to the VLE until they do complete it. After the survey is closed, coordinators and tutors see the feedback from their courses, and managers see all the feedback. A range of Key Performance Indicators are published. The survey is completely anonymous.

\section{The Benefits}

Apart from the benefits of the embedded VLE to students and lecturers, the CMS MLE has had most direct impact on the work of managers and administrators. All users have benefited in some way.

\section{Managers and QA officers}

Access to a range of high level reports and key performance indicators (including lists of students with poor attendance, courses where exam papers have yet to be written, or coursework has not yet been marked, analysis of student surveys and access to student feedback) enable systems to be monitored and corrective action taken if necessary. The Dean of the School has publicly commented that without the CMS MLE, she could not envisage how the School could be managed.

\section{Administrators}

Processing enquiries, dealing with extenuating circumstances claims, and getting exam papers written by deadlines are just some of the benefits. The School office staff have found the student profile to be of particular value when dealing with issues relating to individual students. 


\section{Lecturers}

The student profile is of great value to all tutors, and the course profile is particularly useful for course coordinators. Proposals to use the data about students to calculate an "at risk of failure" index for all students are being considered that could be used by personal tutors to identify and help students in need of support.

\section{Students}

Easy access to all data relevant to them, particularly feedback and an electronic portfolio of their work, means they have a comprehensive record of their university experience. Online systems have meant quicker turnaround times, and access by mobile phones is particularly useful. In a recent survey on the student intranet $96 \%$ of students agreed with the statement that "The Student Intranet [MLE] provided support for my learning". One student commented: "the intranet is as good as any intranet can be in my eyes", and another "Nothing can be improved at the moment. Seems to have everything we need."

\section{External examiners}

Access to reports and student work before, during and after visits, enables external examiners to get a better picture of the work of the course teams, and to give more useful feedback. The electronic submission and record keeping system has been praised by several external examiners in their reports to the university.

\section{The environment}

We all benefit from a (mostly) paperless office. Printing of student courseworks is done double sided on a fast efficient central printer, and many staff use the online systems for marking and feedback. It all helps to support the university's sustainability agenda.

\section{Conclusion}

In conclusion, the CMS MLE should be seen as a prototype of how a comprehensive MLE might be achieved in a university. Many of the benefits from the integration and availability of data in a usable format have been identified and demonstrated on a smaller scale. It is recommended that institutions avoid the temptation to "outsource" systems to a plethora of social Web 2.0 systems which offer short term gains but may give long term pain if they lose control of much valuable data that can enable them to provide a better service to students and their funders. A good MLE can allow lecturers and managers to focus on the purpose of higher education rather than getting overwhelmed by administrative tasks that they perceive to be a hindrance to their vocation. However, whatever system is developed must fit with the business processes of the individual university, so there is no easy "off the shelf" solution. 


\section{References}

JISC (2005). Case Studies of Managed Learning Environments in Further Education. [Online]. Available at: http://www.jiscinfonet.ac.uk/Resources/external-resources/mle-in-fe-case-studies [Accessed on 1 May 2012].

JISC (2006). MLEs for Lifelong Learning Project Briefing Pack. [Online]. Available at: http://www.jisc.ac.uk/ whatwedo/programmes/buildmlehefe/lifelonglearning/mlebriefingpack.aspx [Accessed on 30 April 2012].

Moodle (2012). Philosophy. [Online]. Available at: http://docs.moodle.org/22/en/Philosophy [Accessed on 30 April 2012].

Weller, M. (2007). Virtual Learning Environments: Using, Choosing and Developing Your VLE. London: Taylor \& Francis.

\section{Author Biography}

Dr Ray Stoneham is a principal lecturer at the University of Greenwich and a specialist in data-driven web sites, with a particular interest in intranets and e-learning. He developed and manages several School intranets and the website used by external examiners of the university. 
Compass: The Journal of Learning and Teaching at the University of Greenwich, Issue 6, 2012 